\title{
1
}

\section{Introducing Logistics Systems}

\subsection{Introduction}

Logistics deals with the planning and control of material flows and related information in organizations, both in the public and private sectors. Broadly speaking, its mission is to get the right materials to the right place at the right time, while optimizing a given performance measure (e.g. minimizing total operating costs) and satisfying a given set of constraints (e.g. a budget constraint). In the military context, logistics is concerned with the supply of troops with food, armaments, ammunitions and spare parts, as well as the transport of troops themselves. In civil organizations, logistics issues are encountered in firms producing and distributing physical goods. The key issue is to decide how and when raw materials, semi-finished and finished goods should be acquired, moved and stored. Logistics problems also arise in firms and public organizations producing services. This is the case of garbage collection, mail delivery, public utilities and after-sales service.

Significance of logistics. Logistics is one of the most important activities in modern societies. A few figures can be used to illustrate this assertion. It has been estimated that the total logistics cost incurred by USA organizations in 1997 was 862 billion dollars, corresponding to approximately $11 \%$ of the USA Gross Domestic Product (GDP). This cost is higher than the combined annual USA government expenditure in social security, health services and defence. These figures are similar to those observed for the other North America Free Trade Agreement (NAFTA) countries and for the European Union (EU) countries. Furthermore, logistics costs represent a significant part of a company's sales, as shown in Table 1.1 for EU firms in 1993.

Logistics systems. A logistics system is made up of a set of facilities linked by transportation services. Facilities are sites where materials are processed, e.g. manufactured, stored, sorted, sold or consumed. They include manufacturing and assembly centres, warehouses, distribution centres (DCs), transshipment points, transportation terminals, retail outlets, mail sorting centres, garbage incinerators, dump sites, etc.

Introduction to Logistics Systems Planning and Control G. Ghiani, G. Laporte and R. Musmanno (C) 2004 John Wiley \& Sons, Ltd ISBN: 0-470-84916-9 (HB) 0-470-84917-7 (PB) 
Table 1.1 Logistics costs (as a percentage of GDP) in EU countries (T, transportation; W, warehousing; I, inventory; A, administration).

\begin{tabular}{lccccr}
\hline Sector & T & W & I & A & Total \\
\hline Food/beverage & 3.7 & 2.2 & 2.8 & 1.7 & 10.4 \\
Electronics & 2.0 & 2.0 & 3.8 & 2.5 & 10.3 \\
Chemical & 3.8 & 2.3 & 2.6 & 1.5 & 10.2 \\
Automotive & 2.7 & 2.3 & 2.7 & 1.2 & 8.9 \\
Pharmaceutical & 2.2 & 2.0 & 2.5 & 2.1 & 8.8 \\
Newspapers & 4.7 & 3.0 & 3.6 & 2.1 & 13.4 \\
\hline
\end{tabular}

Transportation services move materials between facilities using vehicles and equipment such as trucks, tractors, trailers, crews, pallets, containers, cars and trains. A few examples will help clarify these concepts.

ExxonMobil Chemical is one of the largest petrochemical companies in the world. Its products include olefins, aromatics, synthetic rubber, polyethylene, polypropylene and oriented polypropylene packaging films. The company operates its 54 manufacturing plants in more than 20 countries and markets its products in more than 130 countries.

The plant located in Brindisi (Italy) is devoted to the manufacturing of oriented polypropylene packaging films for the European market. Films manufactured in Brindisi that need to be metallized are sent to third-party plants located in Italy and in Luxembourg, where a very thin coating of aluminium is applied to one side. As a rule, Italian end-users are supplied directly by the Brindisi plant while customers and third-party plants outside Italy are replenished through the DC located in Milan (Italy). In particular, this warehouse supplies three DCs located in Herstal, Athus and Zeebrugge (Belgium), which in turn replenish customers situated in Eastern Europe, Central Europe and Great Britain, respectively. Further details on the ExxonMobil supply chain can be found in Section 8.2.

The Pfizer Pharmaceuticals Group is the largest pharmaceutical corporation in the world. The company manufactures and distributes a broad assortment of pharmaceutical products meeting essential medical needs, a wide range of consumer products for self-care and well-being, and health products for livestock and pets. The Pfizer logistics system comprises 58 manufacturing sites in five continents producing medicines for more than 150 countries. Because manufacturing pharmaceutical products requires highly specialized and costly machines, each Pfizer plant produces a large amount of a limited number of pharmaceutical ingredients or medicines for an international market. For example, ALFA10, a cardiovascular product, is produced in a unique plant for 
an international market including 90 countries. For this reason, freight transportation plays a key role in the Pfizer supply chain. A more detailed description of the Pfizer logistics system is given in Section 8.3.

Railion is an international carrier, based in Mainz (Germany), whose core business is rail transport. Railion transports a vast range of products, such as steel, coal, iron ore, paper, timber, cars, washing machines, computers as well as chemical products. In 2001 the company moved about 500000 containers. Besides offering high-quality rail transport, Railion is also engaged in the development of integrated logistics systems. This involves close cooperation with third parties, such as road haulage, waterborne transport, forwarding and transshipment companies. More details on the freight rail transportation system at Railion can be found in Section 8.4.

The Gioia Tauro marine terminal is the largest container transshipment hub on the Mediterranean Sea and one of the largest in the world. In 1999, its traffic amounted to 2253 million Twenty-foot Equivalent Units (TEUs). The terminal is linked to nearly 50 end-of-line ports on the Mediterranean Sea. Inside the terminal is a railway station where cars can be loaded or unloaded and convoys can be formed. Section 8.5 is devoted to an in-depth description of the Gioia Tauro terminal.

The waste management system of the regional municipality of Hamilton-Wentworth (Canada) is divided into two major subsystems: the solid waste collection system and the regional disposal system. Each city or town is in charge of its own kerbside garbage collection, using either its own workforce or a contracted service. On the other hand, the regional municipality is responsible for the treatment and disposal of the collected wastes. For the purposes of municipal solid waste planning, the region is divided into 17 districts. The regional management is made up of a waste-to-energy facility, a recycling facility, a 550 acre landfill, a hazardous waste depot and three transfer stations. Section 8.6 contains a more detailed description of this logistics system.

Supply chains. A supply chain is a complex logistics system in which raw materials are converted into finished products and then distributed to the final users (consumers or companies). It includes suppliers, manufacturing centres, warehouses, DCs and retail outlets. Figure 1.1 shows a typical supply chain in which the production and distribution systems are made up of two stages each. In the production system, components and semi-finished parts are produced in two manufacturing centres while finished goods are assembled at a different plant. The distribution system consists 


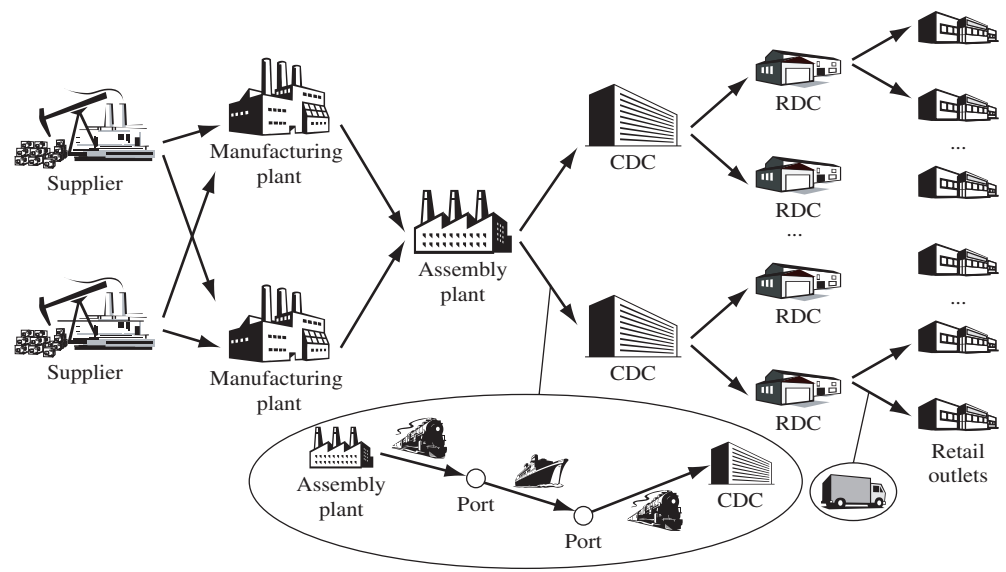

Figure 1.1 A supply chain.

of two central distribution centres (CDCs) supplied directly by the assembly centre, which in turn replenish two regional distribution centres (RDCs) each. Of course, depending on product and demand characteristics it may be more appropriate to design a supply chain without separate manufacturing and assembly centres (or even without an assembly phase), without RDCs or with different kinds of facilities (e.g. crossdocks, see Section 1.2.2). Each of the transportation links in Figure 1.1 could be a simple transportation line (e.g. a truck line) or of a more complex transportation process involving additional facilities (e.g. port terminals) and companies (e.g. truck carriers). Similarly, each facility in Figure 1.1 comprises several devices and subsystems. For example, manufacturing plants contain machines, buffers, belt conveyors or other material handling equipment, while DCs include shelves, forklifts or automatic storage and retrieval systems. Logistics is not normally associated with the detailed planning of material flows inside manufacturing and assembly plants. Strictly speaking, topics like aggregate production planning and machine scheduling are beyond the scope of logistics and are not examined in this textbook. The core logistics issues described in this book are the design and operations of DCs and transportation terminals.

Push versus pull supply chains. Supply chains are often classified as push or pull systems. In a pull (or make-to-order (MTO)) system, finished products are manufactured only when customers require them. Hence, in principle, no inventories are needed at the manufacturer. In a push (or make-to-stock (MTS)) system, production and distribution decisions are based on forecasts. As a result, production anticipates effective demand, and inventories are held in warehouses and at the retailers. Whether a push system is more appropriate than a pull system depends on product features, manufacturing process characteristics, as well as demand volume and variability. MTO systems are more suitable whenever lead times are short, products are costly, and demand is low and highly variable. In some cases, a mixed approach can be used. 
For example, in make-to-assembly (MTA) systems components and semi-finished products are manufactured in a push-based manner while the final assembly stage is pull-based. Hence, the work-in-process inventory at the end of the first stage is used to assemble the finished product as demand arises. These parts are then assembled as soon as customer orders are received.

Product and information flows in a supply chain. Products flow through the supply chain from raw material sources to customers, except for obsolete, damaged and nonfunctioning products which have to be returned to their sources for repair or disposal. Information follows a reverse path. It traverses the supply chain backward from customers to raw material suppliers. In an MTO system, end-user orders are collected by salesmen and then transmitted to manufacturers who in turn order the required components and semi-finished products from their suppliers. Similarly, in an MTS system, past sales are used to forecast future product demand and associated material requirements.

Product and information flows cannot move instantaneously through the supply channel. First, freight transportation between raw material sources, production plants and consumption sites is usually time consuming. Second, manufacturing can take a long time, not only because of processing itself, but also because of the limited plant capacity (not all products in demand can be manufactured at once). Finally, information can flow slowly because order collection, transmission and processing take time, or because retailers place their orders periodically (e.g. once a week), and distributors make their replenishment decisions on a periodic basis (e.g. twice a week).

Degree of vertical integration and third-party logistics. According to a classical economic concept, a supply chain is said to be vertically integrated if its components (raw material sources, plants, transportation system, etc.) belong to a single firm. Fully vertically integrated systems are quite rare. More frequently the supply chain is operated by several independent companies. This is the case of manufacturers buying raw materials from outside suppliers, or using contractors to perform particular services, such as container transportation and warehousing. The relationships between the companies of a supply chain may be transaction based and function specific (as those illustrated in the previous example), or they can be strategic alliances. Strategic alliances include third-party logistics (3PL) and vendor-managed resupply. 3PL is a long-term commitment to use an outside company to perform all or part of a company's product distribution. It allows the company to focus on its core business while leaving distribution to a logistics outsourcer. 3PL is suitable whenever the company is not willing to invest much in transportation and warehousing infrastructures, or whenever the company is unable to take advantage of economies of scale because of low demand. On the other hand, 3PL causes the company to lose control of distribution and may possibly generate higher logistics costs.

Retailer-managed versus vendor-managed resupply. Traditionally, customers (both retailers or final consumers) have been in charge of monitoring their inventory 
levels and place purchase orders to vendors (retailer-managed systems). In recent years, there has been a growth in vendor-managed systems, in which vendors monitor customer sales (or consumption) and inventories through electronic data interchange (EDI), and decide when and how to replenish their customers. Vendors are thus able to achieve cost savings through a better coordination of customer deliveries while customers do not need to allocate costly resources to inventory management. Vendormanaged resupply is popular in the gas and soft drink industries, although it is gaining in popularity in other sectors. In some vendor-managed systems, the retailer owns the goods sitting on the shelves, while in others the inventory belongs to the vendor. In the first case, the retailer is billed only at the time where it makes a sale to a customer.

\subsection{How Logistics Systems Work}

Logistics systems are made up of three main activities: order processing, inventory management and freight transportation.

\subsubsection{Order processing}

Order processing is strictly related to information flows in the logistics system and includes a number of operations. Customers may have to request the products by filling out an order form. These orders are transmitted and checked. The availability of the requested items and customer's credit status are then verified. Later on, items are retrieved from the stock (or produced), packed and delivered along with their shipping documentation. Finally, customers have to be kept informed about the status of their orders.

Traditionally, order processing has been a very time-consuming activity (up to $70 \%$ of the total order-cycle time). However, in recent years it has benefited greatly from advances in electronics and information technology. Bar code scanning allows retailers to rapidly identify the required products and update inventory level records. Laptop computers and modems allow salespeople to check in real time whether a product is available in stock and to enter orders instantaneously. EDI allows companies to enter orders for industrial goods directly in the seller's computer without any paperwork.

\subsubsection{Inventory management}

Inventory management is a key issue in logistics system planning and operations. Inventories are stockpiles of goods waiting to be manufactured, transported or sold. Typical examples are

- components and semi-finished products (work-in-process) waiting to be manufactured or assembled in a plant; 
- merchandise (raw material, components, finished products) transported through the supply chain (in-transit inventory);

- finished products stocked in a DC prior to being sold;

- finished products stored by end-users (consumers or industrial users) to satisfy future needs.

There are several reasons why a logistician may wish to hold inventories in some facilities of the supply chain.

Improving service level. Having a stock of finished goods in warehouses close to customers yields shorter lead times.

Reducing overall logistics cost. Freight transportation is characterized by economies of scale because of high fixed costs. As a result, rather than frequently delivering small orders over long distances, a company may find it more convenient to satisfy customer demand from local warehouses (replenished at low frequency).

Coping with randomness in customer demand and lead times. Inventories of finished goods (safety stocks) help satisfy customer demand even if unexpected peaks of demand or delivery delays occur (due, for example, to unfavourable weather or traffic conditions).

Making seasonal items available throughout the year. Seasonal products can be stored in warehouses at production time and sold in subsequent months.

Speculating on price patterns. Merchandise whose price varies greatly during the year can be purchased when prices are low, then stored and finally sold when prices go up.

Overcoming inefficiencies in managing the logistics system. Inventories may be used to overcome inefficiencies in managing the logistics system (e.g. a distribution company may hold a stock because it is unable to coordinate supply and demand).

Holding an inventory can, however, be very expensive for a number of reasons (see Table 1.1). First, a company that keeps stocks incurs an opportunity (or capital) cost represented by the return on investment the firm would have realized if money had been better invested. Second, warehousing costs must be incurred, whether the warehouse is privately owned, leased or public (see Chapter 4 for a more detailed analysis of inventory costs).

The aim of inventory management is to determine stock levels in order to minimize total operating cost while satisfying customer service requirements. In practice, a good inventory management policy should take into account five issues: (1) the relative importance of customers; (2) the economic significance of the different products; (3) transportation policies; (4) production process flexibility; (5) competitors' policies. 
8

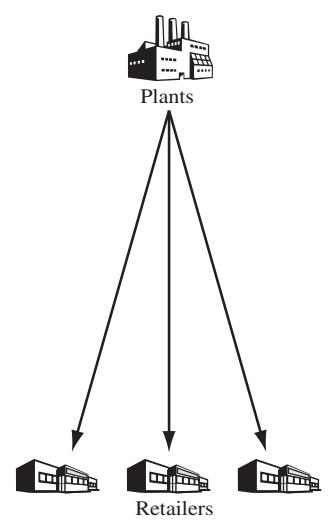

(a)
INTRODUCING LOGISTICS SYSTEMS

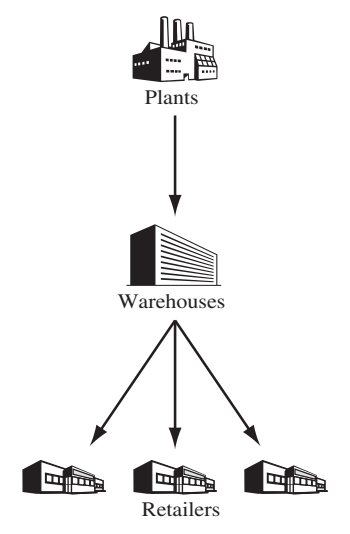

(b)

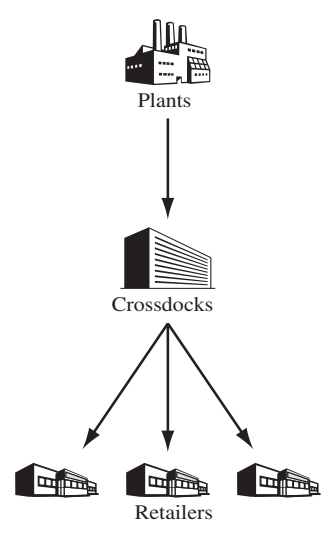

(c)

Figure 1.2 Distribution strategies: (a) direct shipment; (b) warehousing; (c) crossdocking.

Inventory and transportation strategies. Inventory and transportation policies are intertwined. When distributing a product, three main strategies can be used: direct shipment, warehousing, crossdocking.

If a direct shipment strategy is used, goods are shipped directly from the manufacturer to the end-user (the retailers in the case of retail goods) (see Figure 1.2a). Direct shipments eliminate the expenses of operating a DC and reduce lead times. On the other hand, if a typical customer shipment size is small and customers are dispersed over a wide geographic area, a large fleet of small trucks may be required. As a result, direct shipment is common when fully loaded trucks are required by customers or when perishable goods have to be delivered timely.

Warehousing is a traditional approach in which goods are received by warehouses and stored in tanks, pallet racks or on shelves (see Figure 1.2b). When an order arrives, items are retrieved, packed and shipped to the customer. Warehousing consists of four major functions: reception of the incoming goods, storage, order picking and shipping. Out of these four functions, storage and order picking are the most expensive because of inventory holding costs and labour costs, respectively.

Crossdocking (also referred to as just-in-time distribution) is a relatively new logistics technique that has been successfully applied by several retail chains (see Figure 1.2c). A crossdock is a transshipment facility in which incoming shipments (possibly originating from several manufacturers) are sorted, consolidated with other products and transferred directly to outgoing trailers without intermediate storage or order picking. As a result, shipments spend just a few hours at the facility. In predistribution crossdocking, goods are assigned to a retail outlet before the shipment leaves the vendor. In post-distribution crossdocking, the crossdock itself allocates goods to the retail outlets. In order to work properly, crossdocking requires high volume and low variability of demand (otherwise it is difficult to match supply and demand) as well as easy-to-handle products. Moreover, a suitable information system is needed to coordinate inbound and outbound flows. 
Centralized versus decentralized warehousing. If a warehousing strategy is used, one has to decide whether to select a centralized or a decentralized system. In centralized warehousing, a single warehouse serves the whole market, while in decentralized warehousing the market is divided into different zones, each of which is served by a different (smaller) warehouse. Decentralized warehousing leads to reduced lead times since warehouses are much closer to customers. On the other hand, centralized warehousing is characterized by lower facility costs because of larger economies of scale. In addition, if customers' demands are uncorrelated, the aggregate safety stock required by a centralized system is significantly smaller than the sum of the safety stocks in a decentralized system. This phenomenon (known as risk pooling) can be explained qualitatively as follows: under the above hypotheses, if the demand from a customer zone is higher than the average, then there will probably be a customer zone whose demand is below average. Hence, demand originally allocated to a zone can be reallocated to the other and, as a result, lower safety stocks are required. A more quantitative explanation of risk pooling will be given in Section 2.2. Finally, inbound transportation costs (the costs of shipping the goods from manufacturing plants to warehouses) are lower in a centralized system while outbound transportation costs (the costs of delivering the goods from the warehouses to the customers) are lower in a decentralized system.

\subsubsection{Freight transportation}

Freight transportation plays a key role in today's economies as it allows production and consumption to take place at locations that are several hundreds or thousands of kilometres away from each other. As a result, markets are wider, thus stimulating direct competition among manufacturers from different countries and encouraging companies to exploit economies of scale. Moreover, companies in developed countries can take advantage of lower manufacturing wages in developing countries. Finally, perishable goods can be made available in the worldwide market.

Freight transportation often accounts for even two-thirds of the total logistics cost (see Table 1.1) and has a major impact on the level of customer service. It is therefore not surprising that transportation planning plays a key role in logistics system management.

A manufacturer or a distributor can choose among three alternatives to transport its materials. First, the company may operate a private fleet of owned or rented vehicles (private transportation). Second, a carrier may be in charge of transporting materials through direct shipments regulated by a contract (contract transportation). Third, the company can resort to a carrier that uses common resources (vehicles, crews, terminals) to fulfil several client transportation needs (common transportation).

In the remainder of this section, we will illustrate the main features of freight transportation from a logistician's perspective. A more detailed analysis is provided in Chapters 6 and 7. 


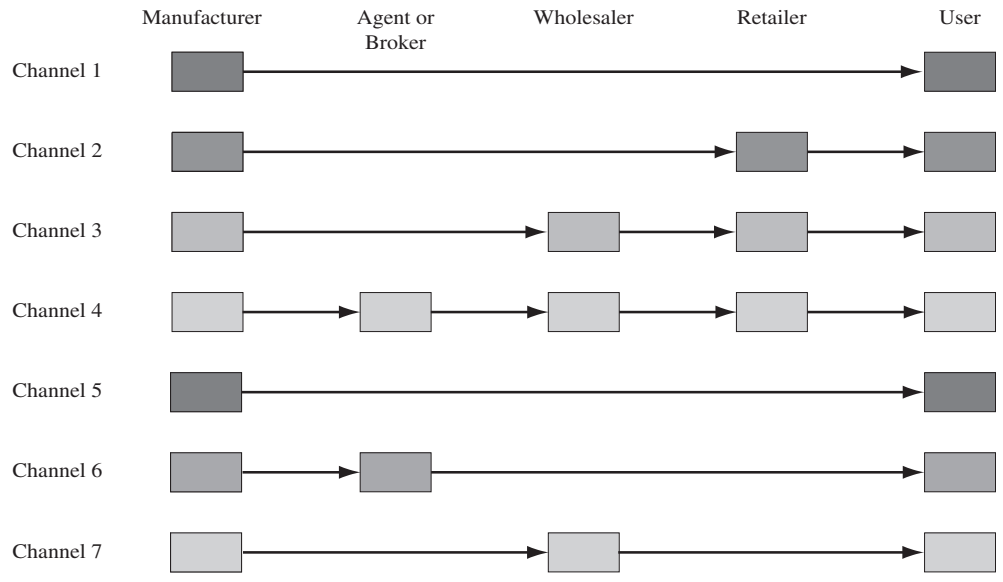

Figure 1.3 Channels of distribution.

Distribution channels. Bringing products to end-users or into retail stores may be a complex process. While a few manufacturing firms sell their own products to endusers directly, in most cases intermediaries participate in product distribution. These can be sales agents or brokers, who act for the manufacturer, or wholesalers, who purchase products from manufacturers and resell them to retailers, who in turn sell them to end-users. Intermediaries add a markup to the cost of a product but on the whole they benefit consumers because they provide lower transportation unit costs than manufacturers would be able to achieve. A distribution channel is a path followed by a product from the manufacturer to the end-user. A relevant marketing decision is to select an appropriate combination of distribution channels for each product. Figure 1.3 illustrates the main distribution channels. Channels 1-4 correspond to consumer goods while channels 5-7 correspond to industrial goods. In channel 1, there are no intermediaries. This approach is suitable for a restricted number of products (cosmetics and encyclopaedias sold door-to-door, handicraft sold at local flea markets, etc.). In channel 2, producers distribute their products through retailers (e.g. in the tyre industry). Channel 3 is popular whenever manufacturers distribute their products only in large quantities and retailers cannot afford to purchase large quantities of goods (e.g. in the food industry). Channel 4 is similar to channel 3 except that manufacturers are represented by sales agents or brokers (e.g. in the clothing industry). Channel 5 is used for most industrial goods (raw material, equipment, etc.). Goods are sold in large quantities so that wholesalers are useless. Channel 6 is the same as channel 5, except that manufacturers are represented by sales agents or brokers. Finally, channel 7 is used for small accessories (paper clips, etc.).

Freight consolidation. A common way to achieve considerable logistics cost savings is to take advantage of economies of scale in transportation by consolidating small shipments into larger ones. Consolidation can be achieved in three ways. First, small shipments that have to be transported over long distances may be consolidated 
Table 1.2 Main features of the most common containers used for transporting solid goods.

\begin{tabular}{crccc}
\hline Type & $\begin{array}{l}\text { Size } \\
\left(\mathrm{m}^{3}\right)\end{array}$ & $\begin{array}{c}\text { Tare } \\
(\mathrm{kg})\end{array}$ & $\begin{array}{c}\text { Capacity } \\
(\mathrm{kg})\end{array}$ & $\begin{array}{c}\text { Capacity } \\
\left(\mathrm{m}^{3}\right)\end{array}$ \\
\hline ISO 20 & $5.899 \times 2.352 \times 2.388$ & 2300 & 21700 & 33.13 \\
ISO 40 & $12.069 \times 2.373 \times 2.405$ & 3850 & 26630 & 67.80 \\
\hline
\end{tabular}

so as to transport large shipments over long distances and small shipments over short distances (facility consolidation). Second, less-than-truckload pick-up and deliveries associated with different locations may be served by the same vehicle on a multi-stop route (multi-stop consolidation). Third, shipment schedules may be adjusted forward or backward so as to make a single large shipment rather than several small ones (temporal consolidation).

Modes of transportation. Transportation services come in a large number of variants. There are five basic modes (ship, rail, truck, air and pipeline), which can be combined in several ways in order to obtain door-to-door services such as those provided, for example, by intermodal carriers and small shipment carriers.

Merchandise is often consolidated into pallets or containers in order to protect it and facilitate handling at terminals. Common pallet sizes are $100 \times 120 \mathrm{~cm}^{2}, 80 \times 100 \mathrm{~cm}^{2}$, $90 \times 110 \mathrm{~cm}^{2}$ and $120 \times 120 \mathrm{~cm}^{2}$. Containers may be refrigerated, ventilated, closed or with upper openings, etc. Containers for transporting liquids have capacities between 14000 and 200001 . The features of the most common containers for transporting solid goods are given in Table 1.2.

When selecting a carrier, a shipper must take two fundamental parameters into account: price (or cost) and transit time.

The cost of a shipper's operated transportation service is the sum of all costs associated with operating terminals and vehicles. The price of a transportation service is simply the rate charged by the carrier to the shipper. A more detailed analysis of such costs is reported in Chapters 6 and 7. Air is the most expensive mode of transportation, followed by truck, rail, pipeline and ship. According to recent surveys, transportation by truck is approximately seven times more expensive than by train, which is four times more costly than by ship.

Transit time is the time a shipment takes to move between its origin to its destination. It is a random variable influenced by weather and traffic conditions. A comparison between the average transit times of the five basic modes is provided in Figure 1.4. One must bear in mind that some modes (e.g. air) have to be used jointly with other modes (e.g. truck) to provide door-to-door transportation. The standard deviation and the coefficient of variation (standard deviation over average transit time) of the transit time are two measures of the reliability of a transportation service (see Table 1.3).

Rail. Rail transportation is inexpensive (especially for long-distance movements), relatively slow and quite unreliable. As a result, the railroad is a slow mover of raw 


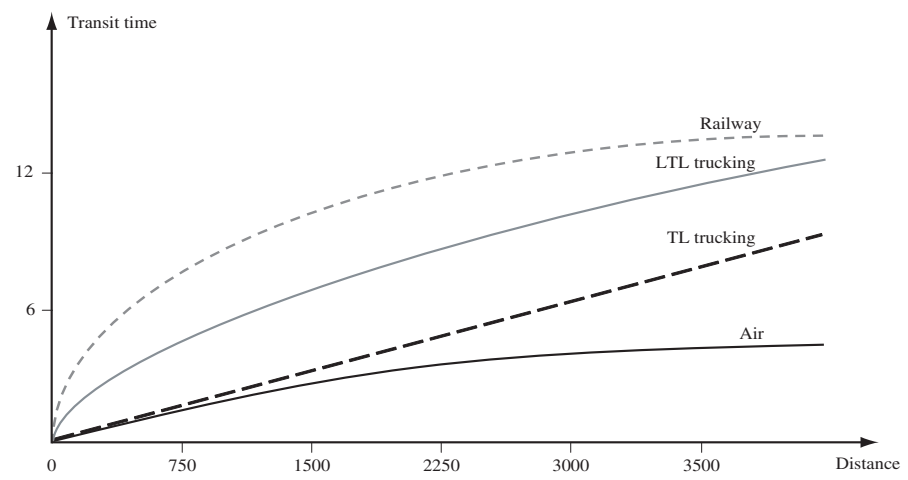

Figure 1.4 Average transit time (in days) as a function of distance (in kilometres) between origin and destination.

Table 1.3 Reliability of the five basic modes of transportation expressed by the standard deviation and the coefficient of variation of the transit time.

\begin{tabular}{ccc}
\hline Ranking & Standard deviation & Coefficient of variation \\
\hline 1 & Pipeline & Pipeline \\
2 & Airplane & Airplane \\
3 & Truck & Train \\
4 & Train & Truck \\
5 & Ship & Ship \\
\hline
\end{tabular}

materials (coal, chemicals, etc.) and of low-value finished products (paper, tinned food, etc.). This is due mainly to three reasons:

- convoys transporting freight have low priority compared to trains transporting passengers;

- direct train connections are quite rare;

- a convoy must include tens of cars in order to be worth operating.

Truck. Trucks are used mainly for moving semi-finished and finished products. Road transportation can be truckload (TL) or less-than-truckload (LTL). A TL service moves a full load directly from its origin to its destination in a single trip (see Figure 1.5). If shipments add up to much less than the vehicle capacity (LTL loads), it is more convenient to resort to several trucking services in conjunction with consolidation terminals rather than use direct shipments (see Figure 1.6). As a result, LTL trucking is slower than TL trucking.

Air. Air transportation is often used along with road transportation in order to provide door-to-door services. While air transportation is in principle very fast, it is 


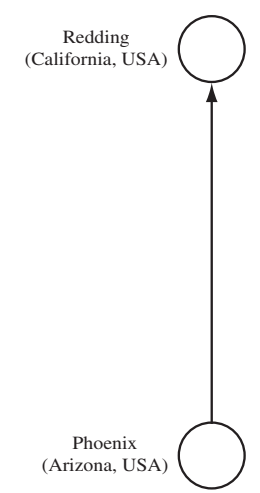

Figure 1.5 Example of TL transportation.

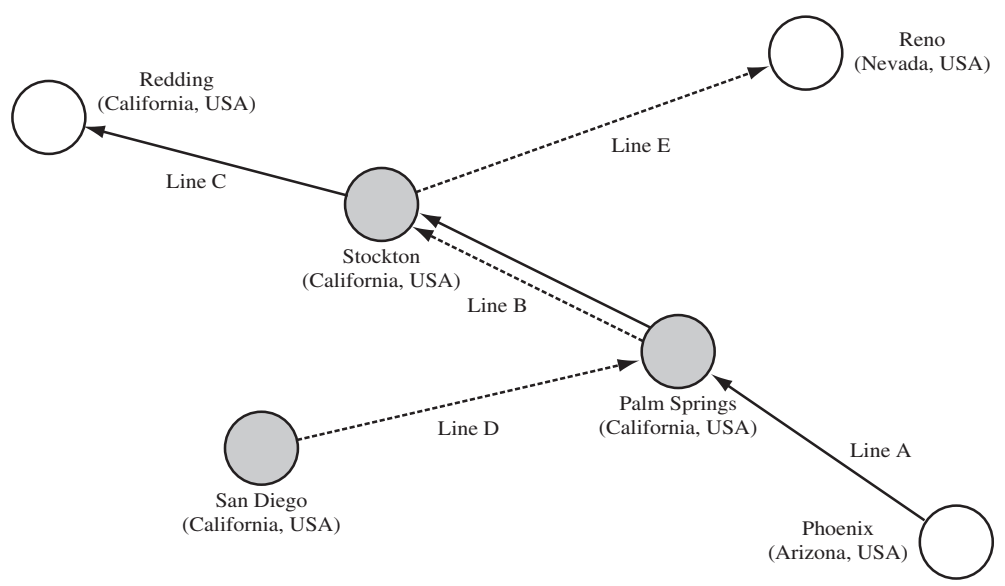

Figure 1.6 Example of LTL transportation.

slowed down in practice by freight handling at airports. Consequently, air transportation is not competitive for short and medium haul shipments. In contrast, it is quite popular for the transportation of high-value products over long distances.

Intermodal transportation. Using more than one mode of transportation can lead to transportation services having a reasonable trade-off between cost and transit time. Although there are in principle several combinations of the five basic modes of transportation, in practice only a few of them turn out to be convenient. The most frequent intermodal services are air-truck (birdyback) transportation, train-truck (piggyback) transportation, ship-truck (fishyback) transportation. Containers are the most common load units in intermodal transportation and can be moved in two ways:

- containers are loaded on a truck and the truck is then loaded onto a train, a ship or an airplane (trailer on flatcar); 
- containers are loaded directly on a train, a ship or an airplane (container on flatcar).

\subsection{Logistics Managerial Issues}

When devising a logistics strategy, managers aim at achieving a suitable compromise between three main objectives: capital reduction, cost reduction and service level improvement.

Capital reduction. The first objective is to reduce as much as possible the level of investment in the logistics system (which depends on owned equipment and inventories). This can be accomplished in a number of ways, for example, by choosing public warehouses instead of privately owned warehouses, and by using common carriers instead of privately owned vehicles. Of course, capital reduction usually comes at the expense of higher operating costs.

Cost reduction. The second objective is to minimize the total cost associated with transportation and storage. For example, one can operate privately owned warehouses and vehicles (provided that sales volume is large enough).

Service level improvement. The level of logistics service greatly influences customer satisfaction which in turn has a major impact on revenues. Thus, improving the logistics service level may increase revenues, especially in markets with homogeneous low-price products where competition is not based on product features.

The level of logistics service is often expressed through the order-cycle time, defined as the elapsed time between the instant a purchase order (or a service request) is issued and the time goods are received by the customer (or service is provided to the user). The order-cycle time is a random variable with a multinomial probability distribution. To illustrate, the probability density function of the supply chain of Figure 1.1 is depicted in Figure 1.7. When a retailer outlet issues an order, the following events may occur:

(a) if the goods required by the outlet are available at the associated RDC, the merchandise will be delivered shortly;

(b) otherwise, the RDC has to resupply its stocks by placing an order to the CDC, in which case the shipment to the retailer will be further delayed;

(c) if the goods are not available even at the CDC, the plants will be requested to produce them.

Let $p_{a}, p_{b}$ and $p_{c}$ be the probabilities of events $a, b$ and $c$, and let $f_{a}(t), f_{b}(t), f_{c}(t)$ be the (conditional) probability density functions of the order-cycle time in case events $a, b$ and $c$ occur, respectively. The probability density function of the order-cycle time is then

$$
f(t)=p_{a} f_{a}(t)+p_{b} f_{b}(t)+p_{c} f_{c}(t) .
$$




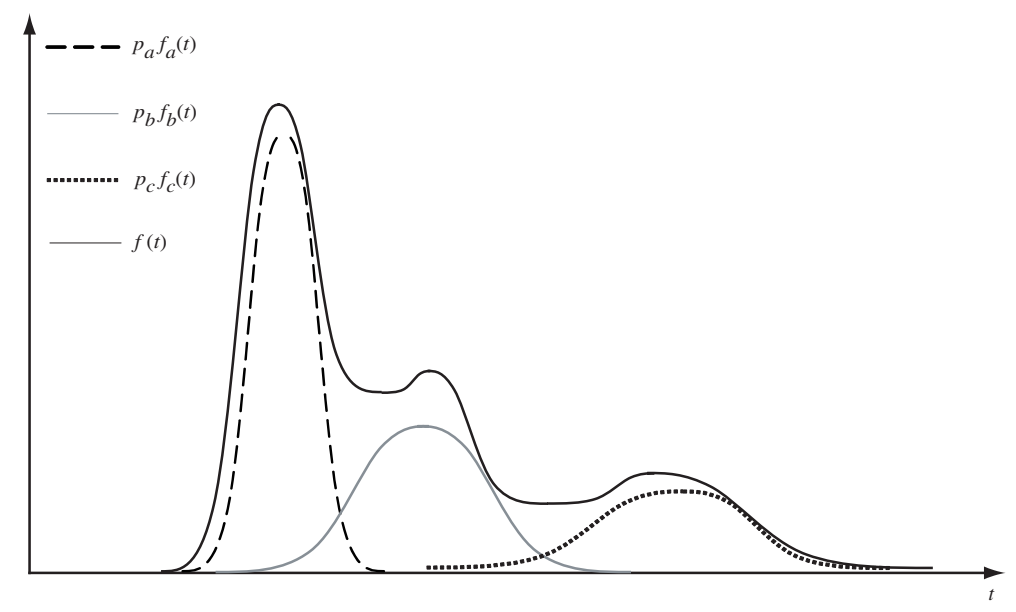

Figure 1.7 Probability density function of the order-cycle time.

Cost versus level of service relationship. Different logistics systems can be classified on the basis of classical multi-objective analysis concepts. Each logistics system is characterized by a level of investment, a cost and a level of service. For example, a system with privately owned warehouses and fleets can be characterized by a high level of investment, a relatively low cost and a high level of logistics service. In what follows the focus will be on the cost-service relationship. System A is said to be dominated by a system $\mathrm{B}$ (see Figure 1.8)) if the cost of $\mathrm{A}$ is higher or equal to the cost of B, the level of service of A is less or equal to the level of service of B and at least one of these two inequalities holds strictly. For example, in Figure 1.8, alternative configurations 2, 3, 4 and 5 are dominated by system 1, while 3, 4, 5 and 7 are dominated by 6 . The undominated alternatives are called efficient (or Pareto optimal) and define the cost versus level of service curve.

Sales versus service relationship. The level of logistics service greatly influences sales volume (see Figure 1.9). If service is poor, few sales are generated. As service approaches that of the competition, the sales volume grows. As service is further improved, sales are captured from competing suppliers (provided that other companies do not change their logistics system). Finally, if service improvements are carried too far, sales continue to increase but at a much slower rate. The sales versus service relationship can be estimated by means of buyer surveys and computer simulations.

Determining the optimal service level. The cost versus level of service and sales versus level of service relationships can be used to determine the level of service that maximizes the profit contribution to the firm, as shown in Figure 1.9. The optimal service level usually lies between the low and high extremes. In practice, a slightly different approach is often used: first, a customer service level is set; then the logistics system is designed in order to meet that service level at minimum cost. 


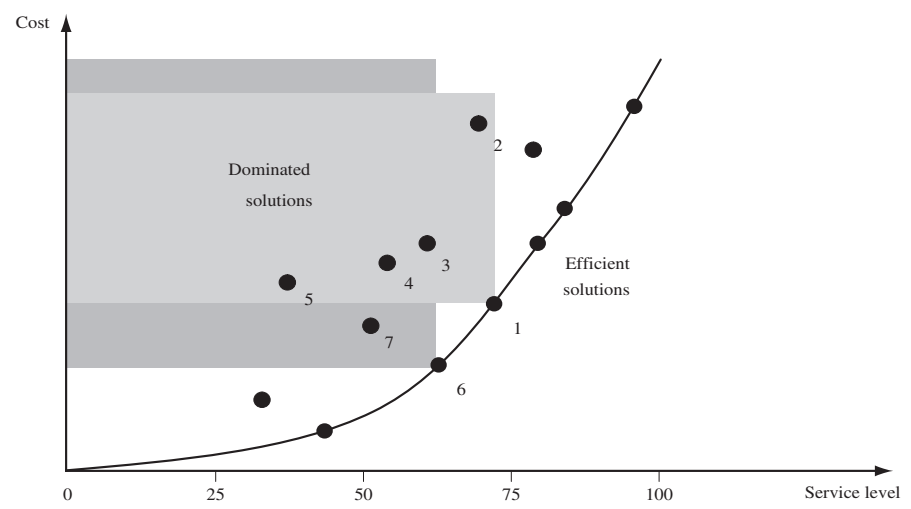

Figure 1.8 Cost versus level of service curve (the level of service is defined as the percentage of orders having an order-cycle time less than or equal to a given number of working days (e.g. four days)).

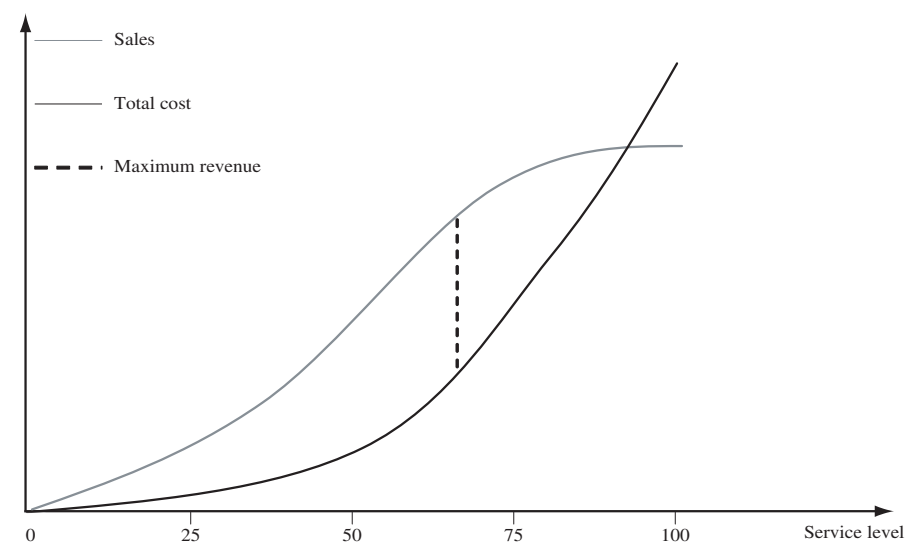

Figure 1.9 Determination of the optimum service level.

\subsection{Emerging Trends in Logistics}

In recent years, several strategic and technological changes have had a marked impact on logistics. Among these, three are worthy of mention: globalization, new information technologies and e-commerce.

Globalization. An increasing number of companies operate at the world level in order to take advantage of lower manufacturing costs or cheap raw materials available in some countries. This is sometimes achieved through acquisitions or strategic alliances with other firms. As a result of globalization, transportation needs have increased. More parts and semi-finished products have to be moved between production sites, and transportation to markets tends to be more complex and costly. The 
Table 1.4 Main differences between traditional logistics and e-logistics.

\begin{tabular}{lcc}
\hline & Traditional logistics & E-logistics \\
\hline Type of load & High volumes & Parcels \\
Customer & Known & Unknown \\
Average order value & $>\$ 1000$ & $<\$ 100$ \\
Destinations & Concentrated & Highly scattered \\
Demand trend & Regular & Lumpy \\
\hline
\end{tabular}

increase in multimodal container transportation is a direct consequence of globalization. Also, as a result of globalization, more emphasis must be put on the efficient design and management of supply chains, sometimes at the world level.

Information technologies. Suppliers and manufacturers make use of EDI. This enables them to share data on stock levels, timing of deliveries, positioning of intransit goods in the supply chain, etc. At the operational level, geographic information systems (GISs), global positioning systems (GPSs) and on-board computers allow dispatchers to keep track of the current position of vehicles and to communicate with drivers. Such technologies are essential to firms engaged in express pick-up and delivery operations, and to long-haul trucking companies.

E-commerce. An increasing number of companies make commercial transactions through the internet. It is common to distinguish between business-to-business (B2B) and business-to-consumers (B2C) transactions. The growth of e-commerce parallels that of globalization and information technologies. As a result of e-commerce the volume of goods between producers and retailers should go down while more direct deliveries should be expected between manufacturers and end-users.

E-commerce leads to a more complex organization of the entire logistics system (e-logistics), which should be able to manage small- and medium-size shipments to a large number of customers, sometimes scattered around the world. Furthermore, the return flow of defective (or rejected) goods becomes a major issue (reverse logistics). Table 1.4 reports the main differences between traditional logistics and e-logistics.

In an e-logistics system different approaches for operating warehouses and distribution are generally adopted. The virtual warehouse and the Points Of Presence In The Territory (POPITT) are just a few examples. A virtual warehouse is a facility where suppliers and distributors keep their goods in stock in such a way that the e-commerce company can fulfil its orders. A POPITT is a company-owned facility where customers may go either for purchasing and fetching the ordered goods, or for returning defective products. Unlike traditional shops, a POPITT only stores already sold goods waiting to be picked up by customers and defective products waiting to be returned to the manufacturers. This solution simplifies distribution management but reduces customer service level since it does not allow for home deliveries. 


\subsection{Logistics Decisions}

When designing and operating a logistics system, one needs to address several fundamental issues. For example, should new facilities (manufacturing and assembly centres, CDCs, RDCs, etc.) be opened? What are their best configuration, size and location? Should any existing facility be divested, displaced or sized down? Where should materials and components be acquired and stored? Where should manufacturing and assembly take place? Where should finished goods be stored? Should warehouses be company-owned or leased? Where should spare parts be stocked? How should production be planned? How should warehouses operate? (Should goods be stored in racks or should they be stacked? Should goods be retrieved by a team of human order pickers or by automated devices?) When and how should each stocking point be resupplied? What mode of transportation should be used to transport products? Should vehicles be company-owned or leased? What is the best fleet size? How should shipment be scheduled? How should vehicles be routed? Should some transportation be carried out by common carriers?

Logistics decisions are traditionally classified as strategic, tactical and operational, according to the planning horizon.

Strategic decisions. Strategic decisions have long-lasting effects (usually over many years). They include logistics systems design and the acquisition of costly resources (facility location, capacity sizing, plant and warehouse layout, fleet sizing). Because data are often incomplete and imprecise, strategic decisions generally use forecasts based on aggregated data (obtained, for example, by grouping individual products into product families and aggregating individual customers into customer zones).

Tactical decisions. Tactical decisions are made on a medium-term basis (e.g. monthly or quarterly) and include production and distribution planning, as well as resource allocation (storage allocation, order picking strategies, transportation mode selection, consolidation strategy). Tactical decisions often use forecasts based on disaggregated data.

Operational decisions. Operational decisions are made on a daily basis or in realtime and have a narrow scope. They include warehouse order picking as well as shipment and vehicle dispatching. Operational decisions are customarily based on very detailed data.

\subsubsection{Decision support methods}

Quantitative analysis is essential for intelligent logistics decision-making. Operations research offers a variety of planning tools.

There are three basic situations in which quantitative analysis may be helpful. 
- If a logistics system already exists, one may wish to compare the current system design (or a current operating policy) to an industry standard.

- One may wish to evaluate specified alternatives. In particular, one may wish to answer a number of what-if questions regarding specified alternatives to the existing system.

- One may wish to generate a configuration (or a policy) which is optimal (or at least good) with respect to a given performance measure.

Benchmarking. Benchmarking consists of comparing the performance of a logistics system to a 'best-practice' standard, i.e. the performance of an industry leader in logistics operations. The most popular logistics benchmarking is based on the supply chain operations references (SCOR) model. The SCOR model makes use of several performance parameters that range from highly aggregated indicators (named key performance indicators (KPIs)) to indicators describing a specific operational issue.

Simulation. Simulation enables the evaluation of the behaviour of a particular configuration or policy by considering the dynamics of the system. For instance, a simulation model can be used to estimate the average order retrieval time in a given warehouse when a specific storage policy is used. Whenever a different alternative has to be evaluated, a new simulation is run. For instance, if the number of order pickers is increased by one, a new simulation is required. Simulation models can easily incorporate a large amount of details, such as individual customer ordering patterns. However, detailed simulations are time consuming and can be heavy when a large number of alternatives are considered.

Optimization. The decision-making process can sometimes be cast as a mathematical optimization problem. 'Easy' (polynomial) optimization problems can be consistently solved within a reasonable amount of time even if instance size is large. This is the case, for example, in linear programming (LP) problems and, in particular, of linear network flow (NF) problems (linear programs with tens of thousands of variables and constraints can be optimized quickly on a personal computer). NPhard optimization problems can be solved consistently within a reasonable amount of time only if instance size is sufficiently small. Most integer programming (IP), mixed-integer programming (MIP), and nonlinear programming (NLP) problems are difficult to optimize. Unfortunately, several classes of logistics decisions (production planning, location decisions, vehicle routing and scheduling, etc.) can only be modelled as IP or MIP problems. This has motivated the development of fast heuristic algorithms that search for good but not necessarily the best solutions. Popular examples of heuristics include rounding the solution of the continuous relaxation of an IP or MIP model, local search, simulated annealing and tabu search. In order to work properly, such procedures must be tailored to the problem at hand. As a result, a slight change to problem features may entail a significant modification to the heuristic. 
Table 1.5 Annual sales forecast and total cost (in millions of dollars) for different service levels.

\begin{tabular}{|c|c|c|c|c|c|c|c|}
\hline & \multicolumn{7}{|c|}{ Percentage of orders filled within three working days } \\
\hline & $70 \%$ & $75 \%$ & $80 \%$ & $85 \%$ & $90 \%$ & $95 \%$ & $100 \%$ \\
\hline Annual sales & 4.48 & 6.67 & 8.17 & 9.34 & 9.87 & 10.56 & 11.52 \\
\hline Annual cost & 4.41 & 5.55 & 5.99 & 6.22 & 6.87 & 7.44 & 12.84 \\
\hline
\end{tabular}

When using an optimization model, a key aspect is to keep model size as small as possible. As a result, unlike simulation models, optimization models do not customarily consider systems dynamics issues.

Continuous approximation methods. Continuous approximation methods can be used whenever customers are so numerous that demand can be seen as a continuous spatial function. Approximation often yields closed-form solutions and can be used as a simple heuristic.

This textbook presents the main mathematical optimization and simulation methods used for decision-making in logistics management. Other approaches such as the SCOR model and the continuous approximation method are described in the references listed at the end of the chapter.

\subsubsection{Outline of the book}

The remainder of this textbook describes the main quantitative methods used for the planning, organizing and controlling of logistics systems. The material is divided into five major streams: forecasting logistics requirements (Chapter 2); designing the logistics network (Chapter 3); managing inventories (Chapter 4); designing and operating warehouses and crossdocks (Chapter 5); planning and controlling long-haul and short-haul freight transportation (Chapters 6 and 7). Finally, Chapter 8 provides supplementary material as well as some case studies that show how efficient logistics plans can be devised by applying or adapting the quantitative methods presented in Chapters 2 to 7.

\subsection{Questions and Problems}

1.1 Why does a push-based supply chain react more slowly to changing demand than a pull-based system?

1.2 Discuss the impact of product diversification (the increase in the number of product variants) on logistics systems planning and control. 
INTRODUCING LOGISTICS SYSTEMS
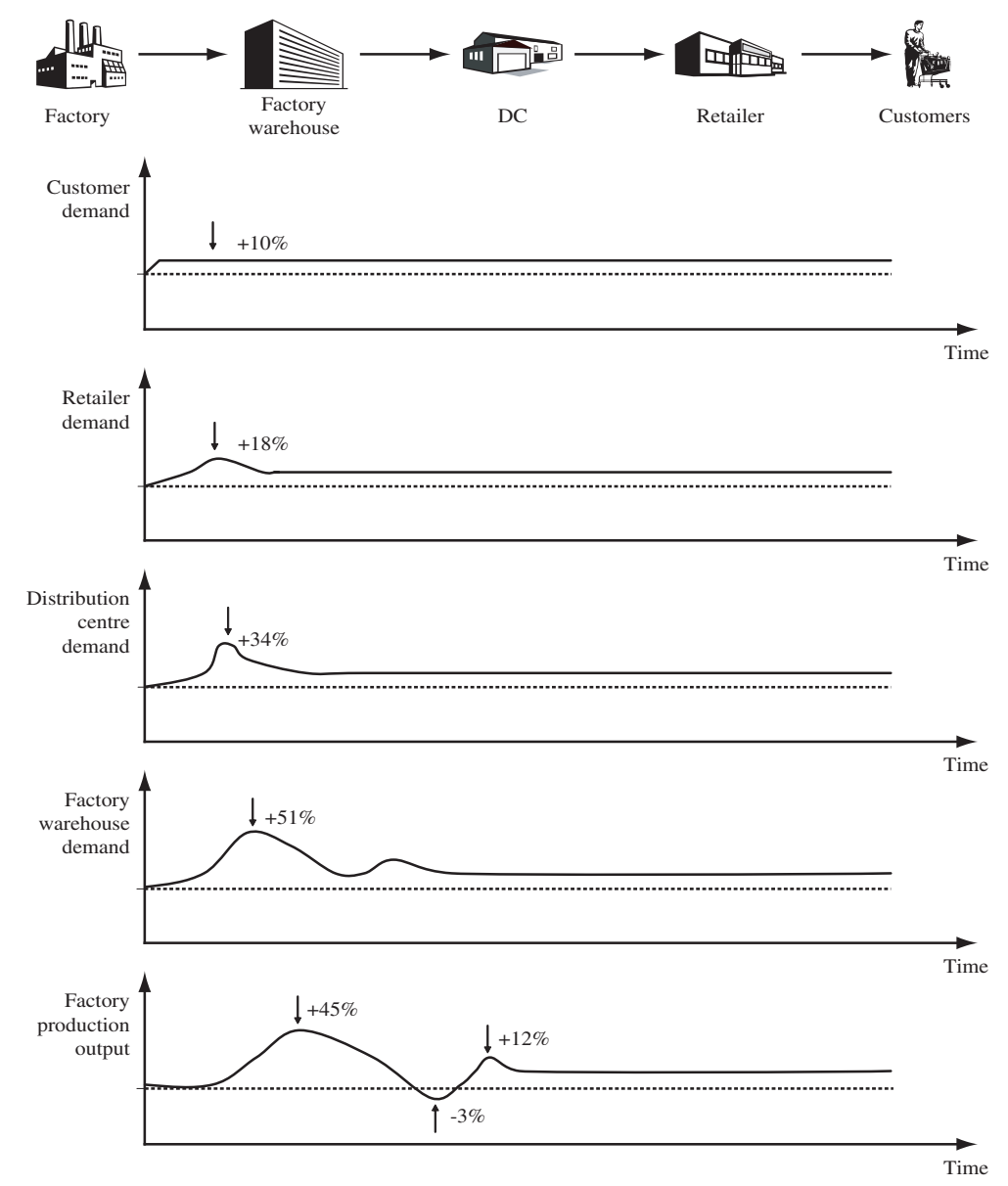

Figure 1.10 The bullwhip effect.

1.3 CalFruit is an emerging Californian distributor of high-quality fresh fruits and vegetables, and packaged food. Because the company operates in a very competitive market, the crucial factor influencing sales volume is the time required to meet orders. On the basis of the historical data, the logistician of the company has estimated that the service level (expressed as the percentage of orders filled within three working days) influences annual sales volume and total cost as reported in Table 1.5. Determine the service level that maximizes revenue.

1.4 Norsk is a Danish producer of dairy products with five subsidiaries in the EU countries and a large network of distributors in North America. The company has recently decided to redesign its Scandinavian distribution network where 140 warehouses have been transformed into pure stocking points, while administrative activities have been concentrated in 14 new regional logistics centres 
and quantitative forecasting data have been centralized at the company's headquarters. List and classify the decisions faced by Norsk management in the logistics system redesign.

1.5 The bullwhip effect is an unwanted increase in variability of material flows over time through the supply chain as a consequence of small variations in customer demand. This phenomenon, which was first recognized by Procter and Gamble managers when examining the demand for Pampers disposal diapers, depends mainly on the fact that individuals managing the different facilities of the supply chain make decisions based on a limited amount of information. For instance, the decision to replenish a factory warehouse is usually based on its current inventory level and the orders actually issued by its immediate successors in the supply chain (e.g. the CDCs) without any knowledge of end-user demand. Traditionally, successor orders are used to develop forecasts of the average value and the standard deviation of the demand perceived by the facility. Then, such estimates serve as a basis for reorder decisions. For example, in the $(s, S)$ method (see Section 4.8), an order is issued any time the inventory level falls below a given reorder level $s$; the inventory level is then increased to an orderup-to-level $S$. As the perceived demand varies, the parameters $S$ and $s$ are updated and order quantities also changed. Show that the typical bullwhip effect for a supply chain made up of a factory, a factory warehouse, a DC and a retailer is like the one reported in Figure 1.10 (where it is assumed that a sudden $10 \%$ increase in end-user demand occurs).

1.6 How can the bullwhip effect be reduced by sharing information among the facilities of a supply chain?

1.7 Discuss the role of transportation mode selection, allocation of transportation cost among subsidiaries, and international taxation when operating a global supply chain.

1.8 Illustrate how a distribution company can take advantage of on-vehicle GPSs.

1.9 Which are the most relevant issues when selecting a company supplier?

1.10 What are the main issues in reverse logistics?

\subsection{Annotated Bibliography}

A detailed introduction to business logistics is:

1. Ballou R 1998 Business Logistics Management: Planning, Organizing, and Controlling the Supply Chain. Prentice Hall, New York.

Statistics reported in Table 1.1 are derived from the following survey:

2. Kearney AT 1993 Logistics Excellence in Europe. European Logistics Association. 
Table 1.4 is taken from:

3. Bayles DL 2000 E-commerce Logistics and Fulfillment: Delivering the Goods. Prentice Hall, New York.

The reference manual to the SCOR approach can be found on the website:

4. Supply Chain Council homepage, http://www.supply-chain.org.

An introductory text to exact and heuristic algorithms for IP and MIP problems is:

5. Wolsey LA 1998 Integer Programming. Wiley, New York.

Continuous approximation methods are surveyed in the book:

6. Daganzo CF 1996 Logistics System Analysis. Springer, Berlin. 
